\title{
HUBUNGAN PERSONAL HYGIENE IBU DAN BALITA DENGAN KEJADIAN DIARE PADA BALITA DI DESA BARENG KECAMATAN BARENG KABUPATEN JOMBANG
}

\author{
The Correlation Of Mother And Toddler's Personal Hygiene With The Incidence Of \\ Diarrhea For Toddlers At Bareng Village, Bareng Sub District In Jombang District
}

\author{
Rizki Emil Linda*, Budi Nugroho, Sestu Retno D.A \\ STIKES PEMKAB Jombang \\ *Email : rizkiemil304@gmail.com
}

\begin{abstract}
ABSTRAK
Penyakit diare masih menjadi salah satu penyebab utama tingginya angka kesakitan dan kematian anak berusia kurang dari 5 tahun. Angka kejadian diare meningkat setiap tahunnya. Ada beberapa faktor yang menyebabkan diare salah satunya yakni personal hygiene ibu dan balita. Penelitian ini bertujuan untuk mengetahui hubungan personal hygiene ibu dan balita dengan kejadian diare pada balita di Desa Bareng Kecamatan Bareng Kabupaten Jombang.

Desain penelitian ini adalah analitik korelasional dengan metode penelitian cross sectional. Variabel penelitian ini adalah Variabel Independen personal hygiene ibu dan balita dan Variabel Dependen kejadian diare pada balita. Populasi penelitian ini adalah Seluruh ibu yang mempunyai balita usia 1-5 tahun di Desa Bareng Kecamatan Bareng Kabupaten Jombang sejumlah 651. Besar sampel 87 diambil menggunakan Cluster Random Sampling. Pengumpulan data dengan menggunakan kuesioner. Penelitian dilakukan pada tanggal 18-27 April 2017 dianalisis dengan uji statistik Chi-Square.

Hasil penelitian menunjukkan bahwa hampir seluruhnya $(86,0 \%)$ responden yang mempunyai personal hygiene positif tidak mengalami diare pada balita. Analisa data dengan menggunakan Chi-Square diperoleh $\rho$-value $0,000<$ a 0,05 berarti bahwa ada hubungan personal hygiene ibu dan balita dengan kejadian diare pada balita di Desa Bareng Kecamatan Bareng Kabupaten Jombang.

Berdasarkan hasil penelitian diketahui bahwa semakin baik personal hygiene maka semakin rendah kejadian diare pada balita. Masyarakat terutama ibu diharapkan dapat meningkatkan kesadaran akan pentingnya menjaga kebersihan diri agar tidak terjadi diare.
\end{abstract}

Kata Kunci : Personal Hygiene, Ibu, Diare, Balita

\section{ABSTRACT}

Diarrheal disease still becomes one of the main causes of morbidity and mortality high rate of children as old as less than 5 years. The incidence of diarrhea increases every year. There are several factors that cause diarrhea, one of them is mother and toddler's personal hygiene. This research aimed to determine the correlation of mother and toddler's personal hygiene with the incidence of diarrhea for toddlers at Bareng Village, Bareng Sub district In Jombang District.

The design of this research was correlation analytic with cross sectional research method. The variables of this research consisted of Independent Variable was mother and toddler's personal hygiene and Dependent variable was the incidence of diarrhea for toddles. The population of research was all mothers and toddler as old as 1-5 years at Bareng Village, Bareng Sub district In Jombang District as many as 651. The total of samples was 87 that was taken by using Cluster Random Sampling. Data collection used questionnaire. The research was conducted on April 18 th $-27^{\text {th }}$ 2017, it was analyzed by Chi-Square statistical test.

The result of research showed that almost all of respondents (86.0\%) who had positive personal hygiene did not experience diarrhea for toddlers. Analysis of data used Chi-Square that was obtained $\rho$ value $0,000<\alpha 0.05$, it meant that there was a correlation of mother and toddler's personal hygiene with the incidence of diarrhea for toddler at Bareng Village, Bareng Sub district In Jombang District.

Based on the result of research was known that the better personal hygiene was, the lower the incidence of diarrhea for toddler was. Community especially mothers are expected to increase the awareness of how important to maintain personal hygiene in order to avoid diarrhea.

Keywords : Personal Hygiene, Mother, Diarrhea, Toddler. 


\section{PENDAHULUAN}

Penyakit diare masih menjadi masalah global dengan derajat kesakitan dan kematian yang tinggi di berbagai negara terutama di negara berkembang, dan juga sebagai salah satu penyebab utama tingginya angka kesakitan dan kematian anak di dunia. Secara umum, diperkirakan lebih dari 10 juta anak berusia kurang dari 5 tahun meninggal setiap tahunnya di dunia dimana sekitar 20\% meninggal karena infeksi diare (Magdarina, 2010 dalam Hardi dkk, 2012).

Menurut data World Health Organization (WHO) pada tahun 2013, setiap tahunnya ada sekitar 1,7 miliar kasus diare dengan angka kematian 760.000 anak dibawah 5 tahun (Siregar dkk, 2016). Berdasarkan hasil Riskesdas (2007) diketahui bahwa prevalensi diare pada balita di Indonesia mengalami peningkatan setiap tahunnya. Riskesdas (2007) melaporkan bahwa angka nasional prevalensi diare adalah 9,0\%. Prevalensi diare berdasarkan kelompok umur pada balita (1-4 tahun) terlihat tinggi menurut hasil Riskesdas (2007), yaitu 16,7\%. Demikian pula pada bayi ( $<1$ tahun), yaitu 16,5\% (Kemenkes RI, 2011 dalam Siregar dkk, 2016). Provinsi Jawa Timur merupakan provinsi yang memberikan kontribusi besar terhadap jumlah kasus diare pada balita di Indonesia. Hal ini dikarenakan Jawa Timur merupakan provinsi dengan jumlah penduduk terbanyak kedua di Indonesia dengan presentase diare pada balita cukup tinggi sebesar 6,6\% (Profil Kesehatan Indonesia, 2013 dalam Ayuningrum dan Salamah, 2015). Berdasarkan data dari Dinas Kesehatan Kabupaten Jombang tahun 2016 jumlah penderita diare yang ditemukan dan ditangani di Kabupaten Jombang adalah 25.978. Sedangkan jumlah penderita diare terbanyak berada di wilayah kerja Puskesmas Bareng dengan jumlah penderita sebanyak 2.231. Berdasarkan data dari Puskesmas Bareng tahun 2016 didapatkan bahwa jumlah penderita diare pada balita sebanyak 669 balita. Dari hasil penemuan didapatkan bahwa diare terbesar pada balita terletak di Desa Bareng dengan jumlah penderita sebanyak 390 balita.

Rendahnya cakupan personal hygiene dan sanitasi lingkungan sering sekali menjadi faktor resiko terjadinya KLB diare (Kemenkes RI, 2011 dalam Mokodompit dkk,
2015). Faktor personal hygiene (kebersihan perorangan) ibu juga sangat berpengaruh terhadap kejadian diare pada balita. Perilaku ibu yang tidak hygienis seperti tidak mencuci tangan pada saat memberi makan anak, tidak mencuci bersih peralatan masak dan makan, dapat menyebabkan balita terkena diare. Personal hygiene ibu dan sanitasi lingkungan perumahan yang baik bisa terwujud apabila didukung oleh perilaku masyarakat yang baik (Depkes RI, 2008 dalam Siregar 2016).

Salah satu upaya yang bisa dilakukan untuk mencegah menyebar dan menularnya diare ialah dengan menjaga kebersihan perorangan karena faktor kebersihan menjadi faktor yang penting untuk menghindarkan anak dari penyakit diare (Fida dan Maya, 2012).

Berdasarkan uraian diatas, maka penulis tertarik untuk melakukan penelitian Hubungan Personal Hygiene Ibu dan Balita Dengan Kejadian Diare Pada Balita Di Desa Bareng Kecamatan Bareng Kabupaten Jombang.

\section{METODE PENELITIAN}

Desain penelitian dalam penelitian ini adalah analitik korelasional dengan metode penelitian cross-sectional. Populasi dalam penelitian ini adalah adalah Seluruh ibu yang mempunyai balita usia 1-5 tahun di Desa Bareng Kecamatan Bareng Kabupaten Jombang tahun 2016 pada bulan Desember sejumlah 651. Sampel dalam penelitian ini adalah Sebagian ibu yang mempunyai balita usia 1-5 tahun di Desa Bareng Kecamatan Bareng Kabupaten Jombang tahun 2016 sejumlah 87. Teknik sampling yang digunakan dalam penelitian ini adalah cluster random sampling yaitu 12 posyandu di Desa Bareng yang terdiri dari posyandu Bareng 1, posyandu Bareng 2, posyandu Bareng 3, posyandu Bareng 4, posyandu Kuwik, posyandu Mojounggul, posyandu Kedung Pring, posyandu Kedung Tanjung, posyandu Tegal Rejo, posyandu Kedunggalih, posyandu Banjarsari, dan posyandu Tegalan. Setelah itu merandom sampel perposyandu yang akan dipakai sebagai responden. Variabel independen personal hygiene ibu dan balita.Variabel dependen kejadian diare pada balita.

Teknik pengumpulan data dalam penelitian ini adalah menggunakan kuesioner. 
Kuesioner yang dibuat oleh peneliti yang melalui uji validitas dan reliabilitas sejumlah 22 soal. Kuesioner berisi tentang personal hygiene ibu dan balita sejumlah 22 soal.

Analisa data pada penelitian ini menggunakan uji statistik chi-square. Penentuan hipotesa diterima atau ditolak adalah jika $\mathrm{x}^{2}$ hitung $\geq \mathrm{x}^{2}$ tabel maka $\mathrm{H}_{0}$ ditolak artinya signifikan. Jika $\mathrm{x}^{2}$ hitung $\leq \mathrm{x}^{2}$ tabel maka $\mathrm{H}_{0}$ diterima artinya tidak signifikan (Hidayat, 2014). Bila $\rho$ value (nilai probabilitas) lebih kecil dari standart signifikan (a : 0,05), maka $\mathrm{H}_{0}$ ditolak (Sugiyono, 2008). Kemudian untuk mengetahui tingkat hubungan kedua variabel dengan memasukkan nilai $\mathrm{x}^{2}$ ke dalam rumus Koefisien Kontingensi (Arikunto, 2010).

\section{HASIL PENELITIAN}

Hasil penelitian akan membahas tentang gambaran tempat penelitian, karakteristik responden, personal hygiene ibu dan balita, kejadian diare pada balita, dan hubungan personal hygiene ibu dan balita dengan kejadian diare pada balita.

Tabel 1 menunjukkan bahwa sebagian besar $(65,5 \%)$ responden berumur 20-35 tahun sebanyak 57 orang. Dan hampir setengahnya $(41,4 \%)$ responden berpendidikan SMP/MTs sebanyak 36 orang. Hampir seluruhnya $(86,2 \%)$ responden bekerja sebagai Ibu Rumah Tangga sebanyak 75 orang. Dan sebagian besar $(64,4 \%)$ responden pernah mendapatkan informasi kesehatan sebanyak 56 orang. Sebagian besar $(63,2 \%)$ responden yang pernah mendapatkan informasi kesehatan dari perugas kesehatan sebanyak 55 orang.

Tabel 2 menunjukkan bahwa sebagian besar $(57,5 \%)$ responden mempunyai personal hygiene positif sebanyak 50 orang. Tabel 3 menunjukkan bahwa sebagian besar (69\%) responden tidak mengalami diare pada balita sebanyak 60 orang. Tabel 4 menunjukkan bahwa hampir seluruhnya $(86 \%)$ responden yang mempunyai personal hygiene positif tidak mengalami diare pada balita sebanyak 43 orang.

Tabel 1 : Distribusi frekuensi Data Umum responden di Desa Bareng Kecamatan Bareng Kecamatan Jombang

\begin{tabular}{|c|c|c|c|}
\hline No & Data Umum & Frekuensi & Presentase $(\%)$ \\
\hline \multirow[t]{4}{*}{1} & Umur & & \\
\hline & $<20$ tahun & 6 & 6,9 \\
\hline & $20-35$ tahun & 57 & 65,5 \\
\hline & $>35$ tahun & 27 & 27,6 \\
\hline \multirow[t]{5}{*}{2} & Tingkat Pendidikan & & \\
\hline & SD & 20 & 23,0 \\
\hline & SMP/MTs & 36 & 41,4 \\
\hline & SMA/MA & 28 & 32,2 \\
\hline & Perguruan Tinggi & 3 & 3,4 \\
\hline \multirow[t]{5}{*}{3} & Pekerjaan & & \\
\hline & Ibu Rumah Tangga & 75 & 86,2 \\
\hline & Wiraswasta & 0 & 0 \\
\hline & Swasta & 6 & 6,9 \\
\hline & PNS & 6 & 6,9 \\
\hline \multirow[t]{3}{*}{4} & Informasi Kesehatan & & \\
\hline & Pernah & 56 & 64,4 \\
\hline & Tidak Pernah & 31 & 35,6 \\
\hline \multirow[t]{5}{*}{5} & Sumber Informasi & & \\
\hline & Tidak pernah & 31 & 35,6 \\
\hline & Petugas Kesehatan & 55 & 63,2 \\
\hline & Radio & 0 & 0 \\
\hline & Majalah/Koran & 1 & 1,1 \\
\hline
\end{tabular}

Sumber : Data Primer 2017 
Tabel 2 Distribusi Frekuensi Karakteristik Responden Berdasarkan Personal Hygiene Ibu dan Balita di Desa Bareng Kecamatan Bareng Kabupaten Jombang

\begin{tabular}{cccc}
\hline No. & Personal Hygiene Ibu dan Balita & Frekuensi & Presentase (\%) \\
\hline 1 & Positif & 50 & 57,5 \\
2 & Negatif & 37 & 42,5 \\
\hline & Total & $\mathbf{8 7}$ & $\mathbf{1 0 0}$ \\
\hline
\end{tabular}

Sumber : Data Primer 2017

Tabel 3 Distribusi Frekuensi Karakteristik Responden Berdasarkan Kejadian Diare Pada Balita di Desa Bareng Kecamatan Bareng Kabupaten Jombang

\begin{tabular}{|c|c|c|c|}
\hline No. & Kejadian Diare & Frekuensi & Presentase $(\%)$ \\
\hline 1 & Tidak Diare & 60 & 69,0 \\
\hline 2 & Diare & 27 & 31,0 \\
\hline \multicolumn{2}{|c|}{ Total } & 87 & 100 \\
\hline
\end{tabular}

Sumber : Data Primer 2017

Tabel 4 Tabulasi Silang Personal Hygiene Ibu dan Balita dengan Kejadian Diare pada Balita di Desa Bareng Kecamatan Bareng Kabupaten Jombang

\begin{tabular}{|c|c|c|c|c|c|c|}
\hline \multirow{3}{*}{ Personal Hygiene } & \multicolumn{4}{|c|}{ Kejadian Diare } & \multirow{2}{*}{\multicolumn{2}{|c|}{ Total }} \\
\hline & \multicolumn{2}{|c|}{ Tidak Diare } & \multicolumn{2}{|c|}{ Diare } & & \\
\hline & $\mathbf{f}$ & $\%$ & f & $\%$ & f & $\%$ \\
\hline Positif & 43 & 86,0 & 7 & 14,0 & 50 & 100 \\
\hline Negatif & 17 & 45,9 & 20 & 54,1 & 37 & 100 \\
\hline
\end{tabular}

Sumber : Data Primer 2017

Hasil hasil uji statistik chi-square menunjukkan bahwa besar nilai $\mathrm{x}^{2}$ hitung adalah 15,939 lebih besar dari $\mathrm{x}^{2}$ tabel 3,841 maka $\mathrm{H}_{0}$ ditolak yang berarti signifikan dengan nilai probabilitas ( $\rho$-value) sebesar 0,000 lebih kecil dari standart signifikan (a) sebesar 0,05 maka $\mathrm{H}_{0}$ ditolak dan $\mathrm{H}_{1}$ diterima yang berarti bahwa ada hubungan personal hygiene ibu dan balita dengan kejadian diare pada balita. Sedangkan tingkat hubungan dilihat dari nilai koefisien kontingensi yakni sebesar 0,393. Dikarenakan nilai koefisien kontingensi 0,393 masuk kedalam interval antara 0,200 - 0,399 maka termasuk kedalam kategori rendah.

\section{PEMBAHASAN}

\section{Personal Hygiene Ibu dan Balita}

Dari hasil penelitian tabel 2 menunjukkan bahwa personal hygiene ibu dan balita di Desa Bareng Kecamatan Bareng Kabupaten Jombang sebagian besar $(57,5 \%)$ responden mempunyai personal hygiene positif sebanyak 50 orang. Personal hygiene merupakan perawatan diri sendiri yang dilakukan untuk mempertahankan kesehatan baik secara fisik maupun psikologis (Aziz Alimul H, 2006 dalam Yuni, 2015). Faktor-faktor yang mempengaruhi personal hygiene adalah praktik sosial, pilihan pribadi, status sosial ekonomi, pengetahuan dan motivasi, variabel budaya, dan kondisi fisik (Isro'in dan Andarmoyo, 2012). Dari tabel dan teori diatas didapatkan bahwa responden mempunyai personal hygiene positif dimungkinkan dipengaruhi oleh salah satunya yaitu pengetahuan. Sedangkan pengetahuan dipengaruhi oleh umur, tingkat pendidikan, pekerjaan dan informasi.

Berdasarkan hasil penelitian didapatkan bahwa sebagian besar $(63,2 \%)$ responden berumur 20-35 tahun mempunyai personal hygiene yang positif sebanyak 36 orang. Menurut Hurlock (1998) dalam Wawan dan Dewi (2010) semakin cukup umur, tingkat kematangan dan kekuatan seseorang akan lebih matang dalam berfikir dan bekerja. Pada masa dewasa merupakan usia produktif. Pembagian usia menurut tingkat kedewasaan yakni 20-30 tahun, 31-40 tahun, dan 41-50 tahun (Hurlock, 2002 dalam Hanifah, 2010). Menurut Hanifah (2010), bertambahnya usia seseorang dapat berpengaruh pada petambahan pengetahuan yang diperoehnya, akan tetapi pada usia-usia tertentu atau menjelang usia lanjut kemampuan penerimaan atau mengingat suatu pengetahuan akan berkurang. Dari uraian tersebut dapat disimpulkan bahwa umur 20 35 tahun termasuk tergolong kedalam usia yang produktif dan tingkat pematangan serta kekuatan dalam berfikir lebih matang, sehingga dalam menerima informasi dapat dipahami dengan baik. Sedangkan usia $<20$ 
tahun belum tinggi kedewasaannya dan usia > 35 tahun merupakan usia menopause sehingga kemampuan penerimaan atau mengingat suatu pengetahuan akan berkurang. Oleh karena itu semakin matang cara berfikir seseorang maka semakin mudah dalam menerima informasi sehingga semakin banyak pengetahuan yang dimiliki maka semakin baik pula praktik personal hygiene seseorang.

Berdasarkan hasil penelitian didapatkan bahwa sebagian besar $(61,1 \%)$ responden berpendidikan SMP/MTs mempunyai personal hygiene yang positif sebanyak 22 orang. Tingkat pendidikan yang terlalu rendah akan sulit memahami pesan atau informasi yang disampaikan. Semakin tinggi tingkat pendidikan seseorang semakin mudah menerima informasi sehingga banyak pula pengetahuan yang dimiliki (Notoatmodjo, 2003). Dari uraian tersebut dapat disimpulkan bahwa tingkat pendidikan SMP bisa lebih menerima informasi dengan mudah dibandingkan pendidikan dasar sehingga semakin banyak pula pengetahuan yang dimiliki. Oleh karena itu semakin banyak pengetahuan yang dimiliki maka semakin baik pula praktik personal hygiene seseorang.

Berdasarkan hasil penelitian didapatkan bahwa sebagian besar $(56,0 \%)$ responden yang berprofesi sebagai Ibu Rumah Tangga mempunyai personal hygiene yang positif sebanyak 42 orang. Menurut Thomas yang dikutip oleh Nursalam (2003), pekerjaan adalah kebutuhan yang harus dilakukan terutama untuk menunjang kehidupannya dan kehidupan keluarga. Bekerja umunya merupakan kegiatan yang menyita waktu. Bekerja akan mempunyai pengaruh terhadap kehidupan keluarga (Wawan dan Dewi, 2010). Dari uraian tersebut dapat disimpulkan bahwa Ibu Rumah Tangga lebih banyak mempunyai waktu luang dan kesempatan untuk menambah wawasan seperti dengan menonton TV, membaca majalah/koran dibandingkan dengan ibu yang bekerja. Dengan demikian dengan banyaknya wawasan yang diperoleh seseorang maka pengetahuan yang dimilki juga semakin banyak sehingga semakin baik pula praktik personal hygiene seseorang.

Berdasarkan hasil penelitian didapatkan bahwa sebagian besar $(62,5 \%)$ responden yang pernah mendapatkan informasi kesehatan mempunyai personal hygiene yang positif sebanyak 35 orang. Informasi adalah keseluruhan makna yang dapat diartikan sebagai pemberitahuan seseorang. Adanya informasi baru membuat suatu hal memberikan landasan kognitif baru bagi terbentuknya sikap terhadap hal-hal tersebut (Notoatmodjo, 2003). Dari uraian diatas disimpulkan bahwa dengan adanya suatu informasi akan menambah wawasan serta pengetahuan seseorang. Seseorang yang pernah mendapatkan informasi akan mempunyai wawasan serta pengetahuan yang lebih luas dibandingkan yang tidak pernah mendapatkan informasi. Sehingga dengan bertambahnya wawasan serta pengetahuan seseorang maka semakin baik pula praktik personal hygiene seseorang.

\section{Kejadian Diare Pada Balita}

Dari hasil penelitian tabel 4.7 menunjukkan bahwa sebagian besar $(69,0 \%)$ responden tidak mengalami diare pada balita sebanyak 60 balita.

Diare dapat diartikan suatu kondisi buang air besar yang tidak normal yaitu lebih dari 3 kali sehari dengan konsistensi tinja yang encer dapat disertai atau tanpa disertai darah atau lendir sebagai akibat dari terjadinya proses inflamasi pada lambung atau usus (Lestari, 2016).

Kuman penyebab diare menyebar melalui mulut (orofecal) antara lain melalui makanan atau minuman akibat tercemar oleh feses dan atau kontak langsung dengan feses penderita, akan tetapi ada beberapa perilaku khusus yang dapat menyebabkan penyebaran kuman enterik dan meningkatkan risiko terjadinya diare (Sodikin, 2011). Faktor lingkungan yang paling dominan yaitu sarana penyediaan air bersih dan pembuangan tinja, kedua faktor ini akan berinteraksi bersama dengan perilaku manusia. Apabila faktor lingkungan tidak sehat karena terkena kuman diare serta berakumulasi dengan perilaku manusia yang tidak sehat pula, maka penularan diare dengan mudah dapat terjadi (Depkes, 2005 dalam Ferlando dan Asfawi, 2014).

Dari tabel dan teori diatas dapat disimpulkan bahwa tidak terjadi diare dimungkinkan karena perilaku ibu yang sehat ditunjang dengan lingkungan yang bersih sehingga balita akan terhindar dari kuman penyebab diare.

\section{Hubungan Personal Hygiene Ibu dan Balita dengan Kejadian Diare Pada Balita}


Dari hasil penelitian tabel 4.7 menunjukkan bahwa hampir seluruhnya $(86,0 \%)$ responden yang mempunyai personal hygiene positif tidak mengalami diare pada balita. Dari hasil uji statistik chi-square menunjukkan bahwa besar nilai $\mathrm{x}^{2}$ hitung adalah 15,939 lebih besar dari $\mathrm{x}^{2}$ tabel 3,841 maka $\mathrm{H}_{0}$ ditolak yang berarti signifikan dengan nilai probabilitas $(\rho-$ value) sebesar 0,000 lebih kecil dari standart signifikan (a) sebesar 0,05 maka $\mathrm{H}_{0}$ ditolak dan $\mathrm{H}_{1}$ diterima yang berarti bahwa ada hubungan personal hygiene ibu dan balita dengan kejadian diare pada balita. Sedangkan tingkat hubungan dilihat dari nilai koefisien kontingensi yakni sebesar 0,393. Dikarenakan nilai koefisien kontingensi 0,393 masuk kedalam interval antara 0,200 - 0,399 maka termasuk kedalam kategori rendah.

Kebersihan perorangan atau personal hygiene adalah suatu tindakan untuk memelihara kebersihan dan kesehatan seseorang (Isro'in dan Andarmoyo, 2012). Ada beberapa faktor yang meningkatkan risiko diare salah satunya yaitu kebersihan perseorangan (Sander, 2005 dalam Ferlando dan Asfawi, 2014). Faktor personal hygiene (kebersihan perorangan) ibu sangat berpengaruh terhadap kejadian diare pada balita (Depkes RI, 2008 dalam Siregar 2016). Selain itu kebersihan perorangan pada anak juga merupakan faktor resiko yang ikut berperan dalam timbulnya diare (Ngastiyah, 2005).

Diare pada balita dapat disebabkan oleh beberapa faktor salah satunya yakni personal hygiene ibu. Personal hygiene ibu yang jelek akan memudahkan menularnya penyakit diare. Perilaku ibu yang tidak hygienis seperti tidak mencuci tangan dan tidak mencuci perlatan masak dan makan yang bersih, dapat menyebabkan balita terkena diare. Selain personal hygiene ibu, kebersihan perorangan anak juga dapat mempengaruhi timbulnya penyakit diare. Akan tetapi dengan menjaga kebersihan terutama kebersihan perorangan baik kebersihan ibu maupun kebersihan anak akan dapat mencegah menularnya penyakit diare. Dari tabel dan teori diatas dapat disimpulkan bahwa semakin baik personal hygiene maka semakin rendah kejadian diare pada balita. Dengan demikian menunjukkan bahwa ada hubungan antara personal hygiene ibu dan balita dengan kejadian diare pada balita dengan tingkat hubungan rendah.

\section{KESIMPULAN DAN SARAN Kesimpulan}

Berdasarkan hasil penelitian didapatkan bahwa:

1. Sebagian besar $(57,5 \%)$ responden mempunyai personal hygiene positif.

2. Sebagian besar $(69,0 \%)$ responden tidak mengalami diare pada balita.

3. Ada hubungan antara personal hygiene ibu dan balita dengan kejadian diare pada balita di Desa Bareng Kecamatan Bareng Kabupaten Jombang yaitu semakin baik personal hygiene maka semakin rendah kejadian diare pada balita dengan tingkat hubungan rendah.

\section{Saran}

Bagi peneliti, diharapkan dapat dijadikan peneliti sebagai acuan untuk selalu meningkatkan pengetahuan dan memberikan informasi kepada masyarakat akan pentingnya menjaga kebersihan diri agar terhindar dari berbagai penyakit terutama penyakit diare.

Bagi peneliti selanjutnya, diharapkan dapat dijadikan sebagai data pendukung dan dapat dikembangkan dalam melakukan penelitian selanjutnya mengingat keterbatasan pada alat ukur yang digunakan peneliti, sehingga disarankan untuk peneliti selanjutnya menggunakan alat ukur lain sebagai alat ukur, agar hasil penelitian lebih akurat lagi dan sempurna. Selain itu diharapkan untuk peneliti selanjutnya agar dapat meneliti faktor-faktor lainnya yang dapat mempengaruhi kejadian diare pada balita.

Bagi Masyarakat, diharapkan dapat meningkatkan kesadaran masyarakat terutama ibu akan pentingnya menjaga kebersihan diri, agar tidak terjadi diare. Selain itu perlu mengajarkan pada anak balita cara menjaga kebersihan diri terutama saat makan makanan dan minuman, setelah bermain, dan setelah buang air besar maupun buang air kecil. Hal ini merupakan salah satu cara untuk menurunkan angka kesakitan dan kematian balita akibat diare.

\section{DAFTAR PUSTAKA}

Arikunto, Suharsimi. 2010. Prosedur Penelitian Suatu Pendekatan Praktik. Jakarta : Rineka Cipta

Ayuningrum, Feby Victiani dan Mutiah Salamah. 2015. Analisis faktor sanitasi dan sumber air minum yang mempengaruhi insiden diare pada balita 
di jawa timur dengan regresi logistik biner. Online http://ejurnal.its.ac.id. Diakses pada tanggal 19 Januari 2017

Fida dan Maya. 2012.Pengantar Kesehatan Anak. Yogyakarta: D-Medika

Ferlando, Herry Tomy dan Supriyono Asfawi. 2014. Hubungan antara sanitasi lingkungan dan personal hygiene ibu dengan kejadian diare pda balita di wilayah kerja puskesmas mangkang tahun 2014. Online http://eprints.dinus.ac.id. Diakses pada tanggal 19 Januari 2017

Hardi, Amir Rahman dkk. 2012. Faktor-faktor yang mempengaruhi diare pada balita di wilayah kerja puskesams baranglompo kecamatan ujung tanah tahun 2012. Online http://repository.unhas.ac.id. Diakses pada tanggal 19 Januari 2017

Hanifah, Maryam. 2010. Hubungan usia dan tingkat pendidikan dengan pengetahuan wanita usia 20-50 tahun tentang periksa payudara sendiri tahun 2010.

Online http://repository.uinjkt.ac.id. Diakses pada tanggal 19 Mei 2017

Isro'in, Laily dan Andarmoyo, Sulistyo. 2012. Personal Hygiene. Yogyakarta: Graha Ilmu

Lestari, Titik. 2016. Asuhan Keperawatan Anak. Yogyakarta: Nuha Medika

Mokodompit, Amanda dkk. 2015. Hubungan tindakan personal hygiene ibu dengan kejadian diare pada balita di puskesmas bilalang kota kotamobagu. Online http://ejournal.unsrat.ac.id. Diakses pada tanggal 19 Januari 2017

Ngastiyah, 2005. Perawatan Anak Sakit. Jakarta: EGC.

Notoatmodjo. 2003. Ilmu Kesehatan Masyarakat : Prinsip-prinsip Dasar. Jakarta: Rineka Cipta

Siregar, Widyana dkk. 2016. Hubungan sanitasi lingkungan dan personal hygiene ibu dengan kejadian diare pada balita di lingkungan pintu angin kelurahan sibolga hilir kecamatan sibolga utarakota sibolga tahun 2016. Online http :// reposi tory. usu. ac. id. Diakses pada tanggal 16 Februari 2017 